\title{
Salience of social security contributions and employment
}

\author{
Iñigo Iturbe-Ormaetxe* \\ Universidad de Alicante
}

April 2014

\begin{abstract}
Social security contributions in most countries are split between employers and employees. According to standard incidence analysis, social security contributions affect employment negatively, but it is irrelevant how they are divided between employers and employees. This paper considers the possibility that: (i) workers perceive a linkage between current contributions and future benefits and, (ii) they value employers contributions less than own contributions, as the former are less "salient." Under these assumptions, I find that employer contributions have a stronger (negative) effect on employment than employee contributions. Furthermore, a change in how contributions are divided that reduces the share of employers is beneficial for employment. Finally, making employers contributions more visible to workers also has a positive effect on employment.
\end{abstract}

Journal of Economic Literature classification numbers: D03, H22, H55, J08

Key words: Payroll tax, social security, tax incidence, tax salience

*Iñigo Iturbe-Ormaetxe, Departamento de Fundamentos del Análisis Económico, Universidad de Alicante, E-03071, Alicante, Spain. E-mail: iturbe@ua.es. I would like to thank Juan José Dolado, Miguel-Angel López García, Adam Sanjurjo, the editor Eckhard Janeba and two anonymous referees for their helpful comments and suggestions. Financial support from Instituto Valenciano de Investigaciones Económicas, Generalitat Valenciana (Prometeo/2013/037) and Ministerio de Economía y Competitividad (ECO2012-34928) are gratefully acknowledged. 


\section{Introduction}

Tax incidence studies the effect of taxes on the distribution of welfare in a society. Its basic insight is that the person who really pays the tax may not be the person who has the legal obligation to make a tax payment (Fullerton and Metcalf (2002)). For example, if government taxes capital, owners of capital can pass on some or even all of the tax to consumers through higher prices or to workers through lower wages. Economists distinguish between statutory incidence, who is legally responsible for the tax, and economic incidence, the change in the distribution of welfare induced by the tax. They differ in that individuals react to taxes by changing their behavior and, consequently, equilibrium prices may also change. As another example, think of payroll taxes. In the USA, the statutory burden of the payroll tax is the same for employers and employees. However, it is generally agreed that the economic burden is borne entirely by workers. ${ }^{1}$ It is not surprising that economists mainly focus on economic incidence.

The textbook prediction of economic theory is that, when markets are competitive, the economic incidence of a tax will be determined by the elasticities of demand and supply, but not by statutory incidence. ${ }^{2}$ In the context of the labor market, this implies that an increase of contributions paid by employers has the same negative effect on employment as an increase of the same size in contributions paid by employees. Moreover, any change in how contributions are split between employers and employees that keeps the total level of contribution fixed, has no effect either on the level of employment or on the total cost of labor. ${ }^{3}$ Quoting Salanié (2003, p. 16):

"Whether the employer "pays" 80 percent or 50 percent or 20 percent of payroll taxes is immaterial to the equilibrium gross and net wages and to the determination of employment."

I here challenge this view in a purely competitive labor market. I find that the particular way in which payroll taxes are split between employers and employees truly matters, both for gross and net wages and also for employment. To obtain this result I depart from standard analysis by introducing two assumptions:

1. Workers perceive these taxes paid as equivalent to deferred payments and, therefore, not as pure taxes.

\footnotetext{
${ }^{1}$ Fullerton and Metcalf (2002).

${ }^{2}$ Statutory incidence matters for real incidence when there is a (binding) minimum price.

${ }^{3}$ This result does not extend to non-competitive labor markets. See, for example, Pissarides (1998) and Koskela and Schöb (1999).
} 
2. Workers value contributions paid by themselves more than those paid by employers, the reason being that the latter are less "salient" to them.

The first assumption is fairly standard in the literature of public pensions. ${ }^{4}$ The government uses the revenue collected from payroll taxes to finance different public programs that benefit workers. Workers may perceive a linkage between taxes paid today and future benefits. Taken to the extreme, if workers perceive future benefits as actuarial, payroll taxes will have no distortionary effects.

The second assumption deserves more discussion. I begin by noting that in most countries employers and employees share the statutory burden of the payroll tax. In Figure A.1, I represent contributions paid by employers and employees in the OECD countries. Average contribution by employers is $17.71 \%$, while it is $9.76 \%$ for employees. The ratio of the employer contribution to the sum of the employer and the employee contribution ranges from 0 (Denmark and Chile) to 1 (Australia), with a mean of 0.64 . Contrary to employees, employers should perceive their part of the payroll tax as a pure tax, as they do not get any future benefit from it and, as long as they can, they will try to shift the burden of the tax to their employees. Whether they will be successful or not will depend on the corresponding elasticities of supply and demand, as commented above.

Regarding employees, they may value taxes paid by the employer differently from taxes paid by themselves. One reason for this is that they may not be fully aware of taxes paid by the employer on their behalf, or they may not know the true size of those taxes. There is some evidence pointing out in this direction. In a very interesting paper, Boeri, Börsch-Supan and Tabellini (2001) survey the opinions of 5,500 citizens in four European countries (France, Germany, Italy and Spain) on their welfare states and also on different possibilities of reform. One question asked for an estimate of the combined employer and employee contribution. The questions was: "As you know, both employers and employees pay pension contributions. Which fraction of your gross monthly wage goes to public pensions? (Please take into account also your employer contributions)." Several brackets were suggested. In Spain, the brackets were 0-21, 21-35, 35+. The correct answer is 21-35. Half of individuals did not answer the question. Among those who answered (49.2\%), only $28 \%$ answered correctly while $68 \%$ chose the first bracket

\footnotetext{
${ }^{4}$ See, for instance, Feldstein and Liebman (2002). Some earlier examples are Summers (1989) and Gruber (1997).
} 
$(0-21)^{5}$

Recently, Fundación Edad y Vida questioned a sample of 1,200 individuals about their knowledge of the welfare state in Spain and about different reform proposals. According to the answers, individuals seem to over-value worker contributions and under-value employer contributions. In particular, one question asks for an estimate of the contributions paid by the worker. Only $26 \%$ of respondents answer correctly. Interestingly, $30 \%$ choose a value above the correct one, while only $2.5 \%$ choose a value below the correct one. The remaining $41 \%$ do not answer the question. Another question asks for the combined employer and employee contribution. Most individuals do not answer (65\%). Of those who answer (35\%), only $44 \%$ choose the right answer, $34 \%$ choose a value below the correct one and $22 \%$ choose a value above the correct one. ${ }^{6}$

One possible explanation for this underestimation is that workers are only fully aware of the contributions paid by themselves, but ignore or are not very sure about the size of contributions paid by employers. In Spain, for instance, contributions paid by employers do not even appear in the payroll statements that employees receive every month with their wages. ${ }^{7}$ Their own contributions are, on the contrary, fully reflected. This is related to the literature on the "visibility" of taxes that goes back to Buchanan and Wagner (1977). In particular, different authors have studied whether or not the sharing of payroll taxes is irrelevant. Dušek (2002) finds that, contrary to his initial intuition, countries where employer's share is large tend to have small pension programs. Mulligan, Gil, and Sala-i-Martin (2010) find that the employer's share is slightly higher in democracies than in nondemocracies. ${ }^{8}$ They also find that the share paid by the employee has a positive effect on the size of the program, although this effect is rather small. Chetty, Looney and Kroft (2009) have coined the term "salience" to refer to those taxes that are less visible for consumers. Their main contribution is to show that commodity taxes that are included in posted prices observed by consumers have a larger effect on demand than taxes that are not included in posted prices. For instance, if an excise tax is included in the posted price, but a sales tax is not, consumers will react less to changes in the sales tax than to

\footnotetext{
${ }^{5}$ In another survey conducted by the same authors in Germany and Italy, only $20 \%$ of respondents know the overall (employer plus employee) contribution rate approximately. See Tabellini, Börsch-Supan and Boeri (2002).

${ }^{6}$ See Domínguez et al. (2010).

${ }^{7}$ There are countries in which workers also receive information on contributions paid by their employers. In the USA workers get this information in their Social Security Statements. Unfortunately, the Social Security Administration has recently decided to stop mailing the statements due to budgetary restrictions.

${ }^{8}$ See also Mulligan and Sala-i-Martin (1999).
} 
changes in the excise tax. They claim that the reason is not that consumers ignore the sales tax, but that they simply do not bother to compute tax-inclusive prices. They also derive interesting implications for the efficiency costs of taxation. In the standard set-up, taxes that affect demand very little entail small efficiency costs. This result breaks down with inattentive consumers. Consumers may end up spending too much on the taxed good, reducing consumption of other commodities. ${ }^{9}$

Other authors have extended this paper by analyzing the issue of optimal tax design under the presence of "salience effects." For instance, Goldin (2013) studies the problem of a benevolent government that has to choose between high- and low-salience taxes on a particular good in order to raise some required amount of money.

The argument of my paper is this: workers may not fully consider contributions paid as taxes, since they acknowledge that these taxes give them the right to future benefits. Additionally, they behave myopically in the sense that they place a higher value on the contributions paid by themselves than in the contributions paid by the employers, because the latter are less salient. My paper is related to Chetty et al. in that I claim that, from the viewpoint of workers, contributions paid by firms (the sales tax in Chetty et al.) are less salient than contributions paid by workers (the excise tax in Chetty et al.). However, the difference is that under the two assumptions I introduce, changes in either employer or employee contributions have little effect on labor supply. Then, a policy reform that moves part of the burden from firms to workers will have a positive effect on employment. The intuition is that this policy change affects very little labor supply, but has a positive effect on labor demand.

In Section 2, I show that, provided workers value contributions, but employer contributions are less salient for them, the negative effect of taxes on employment is stronger for employer contributions than for employee contributions. Next, I consider three alternative reforms that entail a reduction of the less "salient" tax (employer contributions) coupled with an increase in the most "salient" tax (worker contributions). I find that these reforms have, in general, a positive effect on the equilibrium level of employment and also on welfare. The three reforms differ with respect to the effect on total tax revenue. In Section 3 I study a model based on the Mortensen-Pissarides search and matching model. Interestingly, I find that the results of Section 2 carry over to this new framework. In particular, the reforms studied in those sections have the effect of reducing

\footnotetext{
${ }^{9}$ See also Chetty (2009), Finkelstein (2009), Goldin and Homonoff (2013), and Cabral and Hoxby (2012).
} 
the equilibrium level of unemployment. Section 4 concludes.

\section{Partial equilibrium: the competitive case}

To illustrate my argument I will use the simplest possible model of a competitive labor market. ${ }^{10}$ Labor demand is $D\left(w_{F}\right)$, where $w_{F}=\left(1+\tau_{F}\right) w$ and $D^{\prime}(\cdot) \leq 0$. Here $w_{F}$ is total labor cost for the firm, $w$ is the posted wage that the firm pays to workers, and $\tau_{F}$ is the payroll tax rate paid by the firm. The value of social security contributions paid by the firm is $\tau_{F} w$. I want to stress that what matters for firms is $w_{F}$, not $w$.

Workers receive a net wage $w_{N}=\left(1-\tau_{W}\right) w$, where $\tau_{W}$ is the payroll tax rate paid by workers. The value of social security contributions paid by the worker is $\tau_{W} w$. Defining $\tau=\tau_{F}+\tau_{W}$, per worker revenue of the social security administration is $\tau w=\left(\tau_{F}+\tau_{W}\right) w$.

Since $w_{N}=\left[\left(1-\tau_{W}\right) /\left(1+\tau_{F}\right)\right] w_{F}=\left[1-\left(\tau_{W}+\tau_{F}\right) /\left(1+\tau_{F}\right)\right] w_{F}$, the combination of firm and worker payroll taxes is equivalent to a combined tax rate $T=\left(\tau_{W}+\tau_{F}\right) /(1+$ $\left.\tau_{F}\right)=\tau /\left(1+\tau_{F}\right){ }^{11}$

In a standard labor market model, labor supply would be $S\left(w_{N}\right)$, with $S^{\prime}(\cdot) \geq 0$. As I said in the Introduction, I depart from this standard formulation in two directions. First, workers may perceive contributions as deferred payments, since those contributions are buying them some future benefits. Since these benefits will be collected in the future, workers discount them by a factor $\delta$. This parameter $\delta$ captures the strength of the perceived linkage between contributions and benefits. It reflects not only pure discounting, but also institutional features of social security. For instance, how close to an actuarially fair scheme is the social security system. If benefits are strictly proportional to contributions, all workers will have similar values of $\delta$. If social security is progressive, low-skilled workers may have a higher value of $\delta$ than high-skilled workers. The case $\delta=0$ corresponds to a situation in which social security contributions are perceived as pure taxes. In many countries this can be the case for young workers since their current earnings will not enter the formula used to calculate their future retirement benefits. This could likewise be the case of low-skilled workers who will qualify for a minimum pension.

Second, as discussed in Section 1, contributions paid by the worker and contributions paid by the firm may not be equally salient. To model this asymmetry, I introduce a parameter $\varphi$ that takes values between 0 and 1 and that multiplies contributions paid by

\footnotetext{
${ }^{10}$ This model can be seen as a reduced-form of a standard intertemporal labor decision model.

${ }^{11}$ This is similar to Saez, Matsaganis, and Tsakloglou (2012).
} 
the firm. This parameter captures how salient are employer contributions. The higher is $\varphi$, the more "salient" they are. When $\varphi=1$, they are equally salient for the worker as are worker's contributions. When $\varphi=0$ they are not salient at all.

To sum up, I assume that labor supply is $S\left(w_{W}\right)$, where $w_{W}=\left(1-\tau_{W}\right) w+\delta\left(\tau_{W}+\right.$ $\left.\varphi \tau_{F}\right) w$ and $S^{\prime}(\cdot) \geq 0$. This formulation can be seen as a re-parametrization of Gruber (1997). ${ }^{12}$ Employee contributions are discounted by a factor $\delta$, while employer contributions are discounted by $\varphi \delta \leq \delta$. To save notation, I define $\alpha=\left(1-\tau_{W}\right)+\delta\left(\tau_{W}+\varphi \tau_{F}\right)$. Then, $w_{W}=\alpha w$. Note that if $\delta=0$, we are back to the standard model of labor supply.

At the market equilibrium $D\left(\left(1+\tau_{F}\right) w\right) \equiv S(\alpha w)$. I consider changes in $\tau_{F}$ and $\tau_{W}$ and compare how they affect the equilibrium level of employment. I begin by studying the effect of a change in $\tau_{F}$. I differentiate completely the equilibrium condition to get $D^{\prime}\left(\left(1+\tau_{F}\right) d w+w d \tau_{F}\right) \equiv S^{\prime}(\alpha d w+w d \alpha)$. Since $d \alpha=\delta \varphi d \tau_{F}$, I have:

$$
D^{\prime}\left(\left(1+\tau_{F}\right) \frac{d w}{w d \tau_{F}}+1\right) \equiv S^{\prime}\left(\alpha \frac{d w}{w d \tau_{F}}+\delta \varphi\right) .
$$

Given that $\frac{d w}{w d \tau_{F}}=\frac{d \ln w}{d \tau_{F}}$, that $\frac{d \ln w_{F}}{d \tau_{F}}=\frac{d \ln w}{d \tau_{F}}+\frac{1}{1+\tau_{F}}$, and defining wage elasticities of labor demand and supply (in absolute value) as $\varepsilon_{D}=-D^{\prime} \frac{w}{D}$ and $\varepsilon_{S}=S^{\prime} \frac{w}{S}$, respectively, I obtain that the effect on total labor costs is:

$$
\frac{d \ln w_{F}}{d \tau_{F}}=\frac{\left(1-\tau_{W}(1-\delta)-\delta \varphi\right) \varepsilon_{S}}{\left(1+\tau_{F}\right)\left(\alpha \varepsilon_{S}+\left(1+\tau_{F}\right) \varepsilon_{D}\right)}
$$

The effect of a change in $\tau_{F}$ on the equilibrium level of employment is:

$$
\frac{d \ln L}{d \tau_{F}}=-\frac{\varepsilon_{D} \varepsilon_{S}}{\alpha \varepsilon_{S}+\left(1+\tau_{F}\right) \varepsilon_{D}}\left(1-\tau_{W}(1-\delta)-\delta \varphi\right) .
$$

The derivative in (2) is positive and the derivative in (3) is negative. ${ }^{13}$ This is not surprising, a rise in $\tau_{F}$ increases total labor costs and reduces employment.

Now I study the effect of a change in employee contributions $\tau_{W}$. In a similar way to the one above, I obtain:

$$
\frac{d \ln w_{F}}{d \tau_{W}}=\frac{(1-\delta) \varepsilon_{S}}{\alpha \varepsilon_{S}+\left(1+\tau_{F}\right) \varepsilon_{D}}
$$

\footnotetext{
${ }^{12}$ Using my notation, Gruber (1997) defines labor supply as:

$$
S=S\left(\left(1-a \tau_{W}\right) w+q \tau_{F} w\right)
$$

where $a$ and $q$ reflect how workers discount their contributions relative to cash income and how they value employer contributions relative to cash income, respectively. I get my formulation by setting $a=1-\delta$, and $q=\delta \varphi$.

${ }^{13}$ To check this, note that we need $1 \geq \tau_{W}(1-\delta)+\delta \varphi$. The term on the right reaches a global maximum when $\delta=\varphi=1$, in which case its value is 1 . In all other cases, its value is below 1 .
} 
which is positive. Finally, the effect on the level of employment is:

$$
\frac{d \ln L}{d \tau_{W}}=-\frac{\varepsilon_{D} \varepsilon_{S}}{\alpha \varepsilon_{S}+\left(1+\tau_{F}\right) \varepsilon_{D}}(1-\delta)\left(1+\tau_{F}\right),
$$

which has a negative sign, as $\frac{d \ln L}{d \tau_{F}}$. Again, a rise in $\tau_{W}$ increases labor costs and reduces employment.

I want to compare the effect on employment of a change in $\tau_{F}$ with a change of the same size in $\tau_{W}$. That is, I want to compare $\left|\frac{d \ln L}{d \tau_{F}}\right|$ with $\left|\frac{d \ln L}{d \tau_{W}}\right|$. Using the above expressions I get:

$$
\left|\frac{d \ln L}{d \tau_{F}}\right|-\left|\frac{d \ln L}{d \tau_{W}}\right|=\frac{\varepsilon_{D} \varepsilon_{S}}{\alpha \varepsilon_{S}+\left(1+\tau_{F}\right) \varepsilon_{D}}[\delta(1-\varphi)-(1-\delta) \tau] .
$$

The term in brackets increases with $\delta$ and falls with $\varphi$. The standard case corresponds to $\delta=0$. In that case the term in brackets is $-\tau$, which means that starting from zero taxation it is irrelevant whether to impose the tax on workers or on firms. The term in brackets reaches a maximum value of 1 at $\delta=1$ and $\varphi=0$. It will be positive if the parameter $\varphi$ is below a certain threshold $\widehat{\varphi}$. In particular:

$$
\varphi<\widehat{\varphi}=\frac{1-(1-\delta)(1+\tau)}{\delta} .
$$

This is the crucial result in this paper. As long as Condition (7) holds I get that $\left|\frac{d \ln L}{d \tau_{F}}\right|>\left|\frac{d \ln L}{d \tau_{W}}\right|:$ the reduction in employment after a $1 \%$ increase in $\tau_{F}$ is higher than the reduction in employment after a $1 \%$ increase in $\tau_{W}$. This same condition guarantees that $\frac{d \ln w_{F}}{d \tau_{F}}>\frac{d \ln w_{F}}{d \tau_{W}}$ : a $1 \%$ increase in $\tau_{F}$ raises more total labor costs than a $1 \%$ increase in $\tau_{W}{ }^{14}$ The intuition for this result is simple. We know that an increase in either $\tau_{F}$ or $\tau_{W}$ is detrimental for employment. However, the negative effect of an increase in $\tau_{W}$ on employment is attenuated because this policy change increases the salience of social security contributions.

If $\varphi=1$ or $\delta<\frac{\tau}{1+\tau}$, Condition (7) is never satisfied. ${ }^{15}$ That is, two necessary conditions for the result are $\varphi<1$, employer contributions are less salient than employee

\footnotetext{
${ }^{14}$ Note that Condition (7) is both necessary and sufficient. That is, if $\varphi>\widehat{\varphi}$, we have that $\left|\frac{d \ln L}{d \tau_{F}}\right|<$ $\left|\frac{d \ln L}{d \tau_{W}}\right|$. However, in this case the difference between both terms is approximately zero as long as both $\tau_{W}$ and $\tau_{F}$ are small. In fact, the difference at the minimum $(\delta=0)$ is:

$$
\left|\frac{d \ln L}{d \tau_{F}}\right|-\left|\frac{d \ln L}{d \tau_{W}}\right|=\frac{-\tau \varepsilon_{D} \varepsilon_{S}}{\left(1-\tau_{W}\right) \varepsilon_{S}+\left(1+\tau_{F}\right) \varepsilon_{D}},
$$

which is close to zero when $\tau$ is small. This is the standard result saying that the effect of an increase in $\tau_{F}$ is equal to the effect of an increase in $\tau_{W}$, since economic incidence is determined only by the elasticities of supply and demand.

${ }^{15}$ If $\delta<\frac{\tau}{1+\tau}$, then $\widehat{\varphi}<0$.
} 
contributions, and $\delta \geq \frac{\tau}{1+\tau}$, workers give some value to contributions paid by themselves. Condition (7) is weaker the lower $\tau$ is and the higher $\delta$ is. This condition says that, for given values of $\tau$ and $\delta$, the parameter $\varphi$ cannot be too large.

To sum up, provided that Condition (7) holds, a reduction of $\tau_{F}$ is more beneficial for employment than a comparable reduction of $\tau_{W}$. Interestingly, if social security is progressive, Condition (7) is more likely to hold for low-skilled workers than for highskilled workers. The reason is that the former may have a higher value of $\delta$, since the system is progressive, and a lower value of $\varphi$, as they may be more myopic than highskilled workers.

Next I compare the effect on employment, on welfare, and on tax revenue of three alternative reforms. All of them have in common that there is a reduction of the less "salient" $\operatorname{tax}\left(\tau_{F}\right)$ together with an increase of the most "salient" $\operatorname{tax}\left(\tau_{W}\right)$. The main conclusion is that, since all of them reduce the excess burden of taxation, they have a positive effect on aggregate welfare.

\subsection{Reform 1: keeping constant the combined tax rate}

This reform reduces $\tau_{F}$ and, at the same time, raises $\tau_{W}$ such that the combined tax rate $T$ remains unchanged. If $d \tau_{F}<0$, the exact increase needed in $\tau_{W}$ is:

$$
d \tau_{W}=-(1-T) d \tau_{F}=\frac{-\left(1-\tau_{W}\right)}{\left(1+\tau_{F}\right)} d \tau_{F}>0 .
$$

For instance, assume that initially $\tau_{W}=0.08$ and $\tau_{F}=0.15$. Then, $\tau=0.23$ and the combined tax rate is $T=0.2$. If we reduce $\tau_{F}$ by 1 percentage point $\left(d \tau_{F}=-0.01\right)$, to keep constant $T$ we have to increase $\tau_{W}$ by 0.8 percentage points $\left(d \tau_{W}=0.008\right)$. The situation after this reform is $\tau_{W}^{\prime}=0.088, \tau_{F}^{\prime}=0.14, \tau^{\prime}=0.228$, while $T$ is still 0.2 .

This reform induces first a negative effect on employment, because of the rise in $\tau_{W}$, and second a positive effect, because of the reduction in $\tau_{F}$. To calculate the overall effect I have to compare these two effects. However, it is immediate to see that $\left|\frac{d \ln L}{(1-T) d \tau_{F}}\right|>\left|\frac{d \ln L}{d \tau_{W}}\right|$ as long as $\varphi<1 / \delta$ which is always the case provided that $\varphi<1$ and $\delta>0$. Then, this reform is always positive for employment. In particular, I get:

$$
\left.\frac{d \ln L}{d \tau_{F}}\right|_{\bar{T}}=\frac{-\varepsilon_{D} \varepsilon_{S}}{\alpha \varepsilon_{S}+\left(1+\tau_{F}\right) \varepsilon_{D}} \frac{\delta(1-\varphi)}{1+\tau_{F}}<0,
$$

where the notation $\bar{T}$ refers to the fact that the combined tax rate is kept constant. It is easy to see that the effect of this policy change on welfare is positive. The reason is that it reduces the deadweight loss of taxation. See Figure 1 below for an illustration. 
In general this reform will reduce total revenue of the social security administration. Total revenue is $R=\left(\tau_{W}+\tau_{F}\right) w L=w_{F} L T$. Since $T$ is fixed with this reform, to find the effect on total tax revenue $R$ we have to study the effect on $w_{F} L$. I find that a reduction on $\tau_{F}$ will have a negative effect on $w_{F} L$ if and only if the elasticity of labor demand is less than $1\left(\varepsilon_{D}<1\right) .{ }^{16}$ According to Hamermesh (1993), the most plausible interval for the elasticity of labor demand is $[0.15,0.75]$. Moreover, he proposes 0.3 as the best point estimate. Then this reform will reduce total revenue $R$.

\subsection{Reform 2: keeping constant $\tau=\tau_{W}+\tau_{F}$}

Now I consider a policy reform in which $d \tau_{W}=-d \tau_{F}>0$, so that $\tau=\tau_{W}+\tau_{F}$ remains unchanged. Using the example above, the situation after this reform would be $\tau_{W}^{\prime}=0.09, \tau_{F}^{\prime}=0.14$. Now the combined tax rate rises to $T^{\prime}=0.2017$. If Condition $(7)$ holds, this policy change reduces total labor costs for firms and has, therefore, a positive effect on employment. Given that $\alpha=\left(1-\tau_{W}\right)+\delta\left(\tau_{W}+\varphi \tau_{F}\right)$, if $d \tau_{W}=-d \tau_{F}$ then $d \alpha=(1-\delta+\delta \varphi) d \tau_{F}$. The effect on total labor cost $w_{F}=w\left(1+\tau_{F}\right)$ is:

$$
\left.\frac{d \ln w_{F}}{d \tau_{F}}\right|_{\bar{\tau}}=\frac{\varepsilon_{S}}{\alpha \varepsilon_{S}+\left(1+\tau_{F}\right) \varepsilon_{D}} \frac{(\delta(1-\varphi)-(1-\delta) \tau)}{1+\tau_{F}} .
$$

The effect on employment is:

$$
\left.\frac{d \ln L}{d \tau_{F}}\right|_{\bar{\tau}}=-\frac{\varepsilon_{D} \varepsilon_{S}}{\alpha \varepsilon_{S}+\left(1+\tau_{F}\right) \varepsilon_{D}} \frac{(\delta(1-\varphi)-(1-\delta) \tau)}{1+\tau_{F}} .
$$

If the parameter $\delta$ is strictly positive, the signs of the derivatives in Equations (10) and (11) are determined by the sign of the term $\delta(1-\varphi)-(1-\delta) \tau$. We know that, under Condition (7), that term is positive. This implies that the expression in Equation (10) is positive and the expression in Equation (11) is negative. That is, shifting some part of the contributions from employers to employees, while holding fixed the total contribution rate, reduces total labor costs for the firm and, thus, has a positive effect on employment. ${ }^{17}$

\footnotetext{
${ }^{16}$ We can compute easily:

$$
\left.\frac{d\left(w_{F} L\right)}{d \tau_{F}}\right|_{\bar{T}}=w_{F} L\left(\frac{\varepsilon_{S} \delta(1-\varphi)}{\alpha \varepsilon_{S}+\left(1+\tau_{F}\right) \varepsilon_{D}} \frac{1}{1+\tau_{F}}\right)\left(1-\varepsilon_{D}\right) .
$$

${ }^{17}$ If $\delta=0$, the term $\left.\frac{d \ln w}{d \tau_{F}}\right|_{\bar{\tau}}$ is approximately -1 , as long as $\tau_{W}$ and $\tau_{F}$ are not very large. This is the classical result of full shifting where the equilibrium wage depends only on the value of $\tau$, and not on how this tax is split between employers and employees. Additionally, when $\delta=0$ both $\left.\frac{d \ln w_{F}}{d \tau_{F}}\right|_{\bar{\tau}}$ and $\left.\frac{d \ln L}{d \tau_{F}}\right|_{\bar{\tau}}$ are approximately zero as long as $\tau$ is small. As long as total tax $\tau$ does not change, labor costs $w_{F}$ and employment $L$ are not affected by how contributions are split between worker and firm. It does not matter who bears the statutory burden of the tax.
} 
Figure 1 here

Figure 1 illustrates the effect of shifting part of employer contributions to employees and can be used to see the intuition behind the result. Dotted lines $D(w)$ and $S(w)$ represent labor demand and supply in the absence of taxes. Thin lines $D\left(w\left(1+\tau_{F}\right)\right)$ and $S(\alpha w)$ represent the initial situation. I then reduce $\tau_{F}$ and raise $\tau_{W}$, holding constant the sum $\tau=\tau_{F}+\tau_{W}$. Since contributions are perceived as pure taxes by firms, the reduction of $\tau_{F}$ to $\tau_{F}^{\prime}$ has a positive effect on employment represented by the shift to the right of labor demand. The rise in worker contributions, from $\tau_{W}$ to $\tau_{W}^{\prime}$, is negative for employment and I represent this with the shift to the left of labor supply. New supply and demand curves are represented in bold lines. In standard models these two effects cancel each other, and total employment remains unchanged. In my model, if Condition (7) holds, this change in the split raises the salient part of contributions, implying that the (negative) effect on supply is always smaller in size than the (positive) effect on demand. The overall effect on employment is positive. In the figure it goes from $L$ to $L^{\prime}$.

The positive effect on welfare is also illustrated in the figure. The initial excess burden is represented by the triangle ADE. This reform reduces the excess burden in an amount that is represented by the trapezoid BDEC, while the excess burden after the reform is represented by the triangle $\mathrm{ABC}$. This reform entails a net gain to society.

The rise in $w_{W}$ may seem counterintuitive. However, recall that $w_{W}$ does not only represent the net wage that workers get, but also the value that workers give to their future benefits. In fact, the net wage $w_{N}$ gets lower with this reform.

Finally, total tax revenue $R=\left(\tau_{W}+\tau_{F}\right) w L$ increases with this reform. As the sum $\tau_{W}+\tau_{F}$ does not change, the effect depends on $w L$. But both $w$ and $L$ rise after the reduction of $\tau_{F}$.

\subsection{Reform 3: a revenue-neutral reform}

This third reform entails a reduction in $\tau_{F}$, coupled with an increase in $\tau_{W}$ by an amount that keeps total revenue $R$ constant. In particular, if $d \tau_{F}<0$, the change needed in $\tau_{W}$ is exactly:

$$
\left.\frac{d \tau_{W}}{d \tau_{F}}\right|_{\bar{R}}=-\frac{\frac{d R}{d \tau_{F}}}{\frac{d R}{d \tau_{W}}}=-\frac{1+\tau\left(\frac{d \ln w}{d \tau_{F}}+\frac{d \ln L}{d \tau_{F}}\right)}{1+\tau\left(\frac{d \ln w}{d \tau_{W}}+\frac{d \ln L}{d \tau_{W}}\right)},
$$


where the notation $\bar{R}$ means that revenue is kept constant.

I focus on the case in which Condition (7) holds. In that case I know that $\left|\frac{d \ln L}{d \tau_{F}}\right|>$ $\left|\frac{d \ln L}{d \tau_{W}}\right|$. I also know that $\frac{d \ln w}{d \tau_{W}}>0$ and $\frac{d \ln w}{d \tau_{F}}<0$. Then, I have that $\left.\frac{d \tau_{W}}{d \tau_{F}}\right|_{\bar{R}}<-1$. A revenue-neutral reduction in $\tau_{F}$ is associated with an overall reduction in $\tau=\tau_{F}+\tau_{W}$. Then, this reform has also a positive effect on employment $L$ and, therefore, on welfare. Finally, the effect on the combined tax rate $T$ is ambiguous.

\subsection{On the size of the effects}

Here I present a numerical example to give an idea of the size of the effects on employment of the three proposals above. To do this I need values for the elasticities of demand and supply and also values for the four parameters in the model: $\tau_{F}, \tau_{W}, \delta$, and $\varphi$. I assume that both elasticities are constant. Following Hamermesh (1993), I choose $\varepsilon_{D}=0.3$. Regarding $\varepsilon_{S}$ a reasonable value can be 0.1 . I take the mean values of $\tau_{F}$ and $\tau_{W}$ in the OECD countries in 2013. In particular, $\tau_{F}=0.1771$ and $\tau_{W}=0.0976$.

Before calculating the effects of the three reforms, I use as a benchmark the case $\delta=0$, which is the standard model of labor supply. For this case I get $\frac{d \ln w_{F}}{d \tau_{F}}=0.1839$, and $\frac{d \ln L}{d \tau_{F}}=-0.0649$. These derivatives correspond to those in Equations (2) and (11), respectively. In the standard model an increase in $\tau_{F}$ from 0.1771 to 0.1871 increases $w_{F}$ a $0.18 \%$, and reduces employment a $0.06 \%$. I will use as a benchmark the effect on employment. To see the size of the effects of the three reforms I do the following. I compute the effect of the three alternative reforms on employment $L$ for different values of $\delta$ and $\varphi$, and I divide that effect by $\left|\frac{d \ln L}{d \tau_{F}}\right|=0.0649$. In this way I get an idea of the relative size of these effects. Table 1 below presents a summary of these effects.

Table 1: The relative size of the effects

\begin{tabular}{ll|rrr} 
& & Reform 1 & Reform 2 & Reform 3 \\
\hline \hline$\delta=0$ & & 0 & -0.258 & 0 \\
\hline$\delta=0.5$ & $\varphi=1$ & 0 & -0.258 & 0 \\
& $\varphi=0.75$ & 0.184 & -0.018 & 0.180 \\
& $\varphi=0.5$ & $\mathbf{0 . 3 0 3}$ & $\mathbf{0 . 1 3 6}$ & $\mathbf{0 . 2 9 7}$ \\
& $\varphi=0.25$ & $\mathbf{0 . 3 8 5}$ & $\mathbf{0 . 2 4 4}$ & $\mathbf{0 . 3 7 8}$ \\
& $\varphi=0$ & $\mathbf{0 . 4 4 6}$ & $\mathbf{0 . 3 2 3}$ & $\mathbf{0 . 4 3 8}$ \\
\hline$\delta=0.75$ & $\varphi=1$ & 0 & -0.258 & 0 \\
& $\varphi=0.75$ & $\mathbf{0 . 3 8 5}$ & $\mathbf{0 . 2 4 4}$ & $\mathbf{0 . 3 8 1}$ \\
& $\varphi=0.5$ & $\mathbf{0 . 5 3 0}$ & $\mathbf{0 . 4 3 3}$ & $\mathbf{0 . 5 2 5}$ \\
& $\varphi=0.25$ & $\mathbf{0 . 6 0 6}$ & $\mathbf{0 . 5 3 2}$ & $\mathbf{0 . 6 0 0}$ \\
& $\varphi=0$ & $\mathbf{0 . 6 5 3}$ & $\mathbf{0 . 5 9 3}$ & $\mathbf{0 . 6 4 7}$ \\
\hline \hline
\end{tabular}


First note that in the standard model $(\delta=0)$, reforms 1 and 3 have no effect at all on employment, while Reform 2 has a negative impact on employment. The same happens when $\delta$ is either 0.5 or 0.75 and $\varphi$ is 1 . This is because in these cases Condition (7) does not hold. In the table I write in bold type those cases where this condition is satisfied. I also see that the relative effect on employment gets higher as $\varphi$ declines. For instance, when $\delta=0.75$ and $\varphi=0.5$, the three reforms have a positive effect on employment that is roughly half of the effect (in absolute value) of an increase in $\tau_{F}$ in the standard model.

I also find that the first reform is the one with a stronger impact on employment, then the third reform, and finally the second reform. However, there is a trade-off between the two objectives of increasing employment and increasing revenue. Reform 1 is the most positive for employment, but entails a reduction in tax revenue. Reform 2 is the most positive for revenue, but has less effect on employment. Finally, Reform 3 is in between the two others. In Table 2 I present a summary of the three reforms in terms of their effects on the combined tax rate $T$, tax revenue $R$, employment and welfare.

Table 2: Summary of the three reforms

\begin{tabular}{r|ccc} 
& Reform 1 & Reform 2 & Reform 3 \\
\hline \hline$T$ & $=$ & $\Uparrow$ & $?$ \\
$\tau=\tau_{W}+\tau_{F}$ & $\Downarrow$ & $=$ & $\Downarrow$ \\
$R$ & $\Downarrow$ & $\Uparrow$ & $=$ \\
$L$ & $\Uparrow$ & $\Uparrow^{*}$ & $\Uparrow^{*}$ \\
Welfare & $\Uparrow$ & $\Uparrow^{*}$ & $\Uparrow^{*}$ \\
\hline \hline
\end{tabular}

* As long as Condition (7) holds.

\section{A model of equilibrium unemployment}

The main drawback of the model in Section 2 is that there is no equilibrium unemployment. Here I build a simple model based on the canonical Mortensen-Pissarides search and matching model to see how a change in the "salience" of the tax affects unemployment (see Mortensen and Pissarides, 1994). I will use the simplest version of the MP model as described in Chapter 1 of Pissarides (2000). This is a model in which different frictions in the labor market produce equilibrium unemployment in the steady state.

Since the extension is very straightforward I will spend some time to discuss only the changes needed to adapt it to my framework. Recall that this simple version of the MP model is described by three equations: (i) the Beveridge curve, (ii) the job creation condition, and (iii) the wage equation. I will present these three equations in turn. 
The Beveridge curve (BC), (Equation (1.5) in Pissarides, 2000) can be written as:

$$
u=\frac{\lambda}{\lambda+\theta q(\theta)}
$$

where $u$ is the unemployment rate, $\theta=v / u$ measures labor market "tightness" $(v$ is the fraction of vacant jobs as a fraction of the labor force), $\lambda$ is the Poisson rate of the shocks to occupied jobs that determines the flow to unemployment, and $q(\theta)$ is the instantaneous probability of a vacancy being filled. The Beveridge curve is obtaining by assuming that the mean rate of unemployment is constant. Then, the flow into unemployment $(\lambda(1-u))$ and the flow out of unemployment $(\theta q(\theta) u)$ must be equal. As it is well known, the properties of the matching technology imply that $q^{\prime}(\theta) \leq 0$. When $\theta$ is high there are many vacancies and firms with a vacancy find it difficult to get a match with an unemployed worker. The Beveridge curve has negative slope in the tightness-unemployment space $(\theta, u)$ and it says that, for given $\lambda$ and $\theta$, there is a unique equilibrium unemployment rate. The two remaining equations of the model will serve to determine the value of market tightness $\theta$.

The job creation curve (Equation (1.9) in Pissarides, 2000) requires a slight modification, since in my setup the cost of labor to firms includes employer contributions. A firm earns $V$ with a vacancy and earns $J$ if the job is filled. The arbitrage equation for a firm with a vacancy is:

$$
r V=-p c+q(\theta)(J-V)
$$

where $r$ is the interest rate and $p c$ is the cost of a vacant job per unit of time. This equation says that the capital cost of the asset $(r V)$ has to be equal to the return on the asset. The return has two components, a "dividend" which is the search cost, plus an expected capital gain, which is the possibility of finding a worker. Since there is free entry of firms with a vacancy, we have $V=0$, and this implies:

$$
J=\frac{p c}{q(\theta)}
$$

The value of a filled job is exactly the expected cost of creating it.

A firm with an occupied job has the arbitrage condition:

$$
r J=p-\left(1+\tau_{F}\right) w-\lambda J
$$

where $p>0$ is the fixed value of a job's output and $\left(1+\tau_{F}\right) w$ is the cost of labor, including payroll taxes paid by the firm. The job yields $p-\left(1+\tau_{F}\right) w$ to the firm but 
there is a risk $\lambda$ of an adverse shock. Using Equation (15), I obtain the job creation (JC) condition:

$$
p-\left(1+\tau_{F}\right) w-\frac{(r+\lambda) p c}{q(\theta)}=0 .
$$

The term $\frac{(r+\lambda) p c}{q(\theta)}$ represents the capitalized value of the firm's hiring costs. The only change with respect to Pissarides is that I have to write $\left(1+\tau_{F}\right) w$ instead of $w$. As long as firm search costs are positive $(c>0)$, workers do not get their marginal product. Again, the fact that $q^{\prime}(\theta) \leq 0$ guarantees that the job creation curve slopes down in the tightness-wage space $(\theta, w)$. When wages are high, job creation is not profitable and the ratio of vacancies to workers is low. The introduction of the employer contribution reduces the value that has an occupied job for the firm. For a given wage $w$, the zero profit condition holds for a lower value of market-tightness. In the space $(\theta, w)$ this means that the introduction of the tax shifts the JC curve to the left.

The wage equation (Equation (1.20) in Pissarides, 2000) is the one that deserves more attention. Workers are risk neutral and care only for the present value of their present and future income streams. A worker earns $\alpha w\left(\right.$ recall that $\left.\alpha\left(1-\tau_{W}\right)+\delta\left(\tau_{W}+\varphi \tau_{F}\right)\right)$ when employed and is searching for a job when unemployed. She earns an unemployment benefit $z$ during search. I assume that the unemployment benefit is untaxed. I call $U$ and $V$ the present discounted value of the income streams of an unemployed and of an employed worker, respectively. The arbitrage equation for an unemployed worker is:

$$
r U=z+\theta q(\theta)(W-U) .
$$

The interpretation is that the capital cost of the asset $(r U)$ has to be equal to the return on the asset. In this case the asset is the human capital of the unemployed worker. The return on the asset contains a "dividend" (the unemployment benefit $z$ ) and an expected capital gain (upgrading from unemployment to employment).

The corresponding arbitrage equation for an employed worker is:

$$
r W=\alpha w+\lambda(U-W)
$$

Again I have on the left the capital cost of the asset $(r W)$ and on the right the return on the asset. The return contains a "dividend" (the wage $\alpha w$, that contains the value that the worker assigns to social contributions) and an expected capital loss (downgrading from employment to unemployment).

I assume that the firm and the worker bargain over the wage. As is standard in the literature, I assume that the expected gains from a match are split between the firm and 
the worker according to the Nash bargaining solution. To compute this solution, I have to calculate the expected gains from a match for the firm and the worker. When the wage is $w_{i}$, the expected return for a firm, $J_{i}$, satisfies the equation:

$$
r J_{i}=p-\left(1+\tau_{F}\right) w_{i}-\lambda J_{i}
$$

In case of disagreement, the standard assumption is that the firm gets 0 .

The expected gain of a match for a worker is $W_{i}$, where:

$$
r W_{i}=\alpha w_{i}-\lambda\left(W_{i}-U\right)
$$

The wage $w_{i}$ obtained from the Nash bargaining solution is the one that maximizes the weighted Nash product:

$$
\max _{w_{i}}\left(W_{i}-U\right)^{\beta}\left(J_{i}-V\right)^{1-\beta}
$$

where $0 \leq \beta \leq 1$ is the worker's "bargaining power." Here the threat point of the worker is unemployment $(U)$ and the threat point for the firm is an unoccupied job $(V=0)$. The first-order condition is:

$$
W_{i}-U=\beta\left(W_{i}+J_{i}-U-V\right) .
$$

Labor obtains a fraction $\beta$ of the total surplus created by a match. Using equations (20) and (21) above, I can convert this into:

$$
w_{i}\left[\alpha(1-\beta)+\beta\left(1+\tau_{F}\right)\right]=r U+\beta(p-r U) .
$$

Without taxes, the term that multiplies $w_{i}$ is equal to 1 , since in that case $\alpha=1$. I use equations (15), (18), (20) and (21) to obtain the aggregate wage equation (WE):

$$
w \Omega=(1-\beta) z+\beta p(1+c \theta)
$$

where $\Omega=\alpha(1-\beta)+\beta\left(1+\tau_{F}\right)$. This equation corresponds to Equation 1.20 in Pissarides (2000). The only difference is the term $\Omega$. The wage equation is upward-sloping in the space $(\theta, w)$. When the number of vacancies per unemployed worker is high, workers have a good outside option and they can ask for a high wage. Note that both the employer and the employee contribution appear in the term $\Omega$. Taxes reduce workers' incentives to search for a job, since employee contributions reduce the net surplus from a job. Again, as in Section 2, the two crucial assumptions of the paper mitigate this negative effect. 
An equilibrium is a triple $(u, \theta, w)$ that satisfies the three equations (13), (17), and (24). The model is recursive and can be solved sequentially. Equations (17) and (24) determine the equilibrium values of $\theta$ and $w$. Once $\theta$ is known, Equation (13) is used to determine $u$.

Now I will use this model to study the effects of some of the reforms studied in Section 2. To save space I will focus only on Reform 2.

We are interested in the effect on $\theta$ of a policy change in which $d \tau_{W}=-d \tau_{F}>0$. The crucial point is to study the effect of this reform on market tightness $\theta$. If this reform has the effect of increasing $\theta$, we know from the Beveridge curve (Equation (13)) that equilibrium unemployment will fall. Then, to see the effect of this reform on market tightness I have to study its effect on the job creation condition (Equation (17)) and on the wage equation (Equation $(24)$ ). The reduction in $\tau_{F}$ gives firms more incentives to open additional vacancies, since the surplus they earn on a job increases. In the space $(\theta, w)$ the reduction in $\tau_{F}$ shifts the JC curve to the right. A given wage $w$ is compatible with a higher vacancy-unemployment ratio as shown in Figure 2 below.

With respect to the wage equation, the increase in employee contributions $\tau_{W}$ raises for workers the net value of the outside option in wage bargaining since the unemployment benefit $z$ is not taxed. Then, the wage curve shifts to the left in the space $(\theta, w)$, as shown in Figure 2 below. To see this, note that the effect of this policy change on the parameter $\Omega$ is:

$$
\frac{d \Omega}{d \tau_{F}}=(1-\beta)(1-\delta+\delta \varphi)+\beta>0 .
$$

Since there is a reduction in $\tau_{F}$, the term $\Omega$ gets lower. So, in principle these two effects go in opposite directions. To see the final effect on $\theta$ I have to see which one of them dominates. However, under the assumptions of the paper we can see that the positive effect on the job creation condition dominates. The intuition is similar to what we have seen in Section 2. Workers place a high value in the deferred benefits they get with the contributions they pay, so an increase in these contributions does not have much impact on the net surplus they get from a job. The formal proof of this net positive effect on $\theta$ is as follows. I substitute wages from (24) into (17) to get:

$$
p-\left(1+\tau_{F}\right)\left(\frac{(1-\beta) z+\beta p(1+c \theta)}{\Omega}\right)-\frac{(r+\lambda) p c}{q(\theta)}=0 .
$$

This equation determines the equilibrium value of $\theta$. The overall effect of the reform on 
market tightness can be obtained by using the Implicit Function Theorem to compute:

$$
\frac{d \theta}{d \tau_{F}}=-\frac{\frac{d(\cdot)}{d \tau_{F}}}{\frac{d(\cdot)}{d \theta}}
$$

where the term $(\cdot)$ is a short-hand for Equation (26). It is easy to check that $\frac{d(\cdot)}{d \theta}<0$. This implies that the sign of $\frac{d \theta}{d \tau_{F}}$ will be the sign of the term in the numerator, $\frac{d(\cdot)}{d \tau_{F}}$. Next, I check that:

$$
\begin{aligned}
\frac{d(\cdot)}{d \tau_{F}} & =\left(p-\frac{(r+\lambda) p c}{q(\theta)}\right) \frac{d \Omega}{d \tau_{F}}-(1-\beta) z-(1+c \theta) \beta p= \\
& =\left(1+\tau_{F}\right) w \frac{d \Omega}{d \tau_{F}}-\Omega w=\left[\left(1+\tau_{F}\right) \frac{d \Omega}{d \tau_{F}}-\Omega\right] w .
\end{aligned}
$$

In the second line I have made used of equations (17) and (24). Interestingly, the term in brackets can be simplified into $(1-\beta)[(1-\delta) \tau-\delta(1-\varphi)]$. This term will be negative if Condition (7) holds. But, since under this policy reform there is a reduction in $\tau_{F}$, this means that equilibrium market tightness $\theta$ will increase. Then, using Equation (13) I know that the equilibrium level of unemployment will be lower.

Figure 2 here

Figure 2 summarizes all the above discussion. Initial market tightness is $\theta_{0}$ in Figure 2. This reform moves the job creation curve to the right and the wage curve to the left. Under Condition (7) the first effect dominates, increasing market tightness to $\theta_{1}$. In the right-hand panel we see that this has the effect of reducing the equilibrium level of unemployment. The intuition is again that, under the assumptions behind Condition (7), this policy reform has little effect on workers behavior.

\section{Final remarks and conclusions}

In this paper I find that, contrary to the prediction of standard economic theory, the way in which social security contributions are split between employers and employees matters for the level of employment. In particular, I find that contributions paid by firms are more harmful for employment than contributions paid by workers. To obtain this result I need two conditions. First, workers must attach some value to social security contributions. Second, workers must value their own contributions more than those paid by employers. 
I consider three alternative reforms that entail a reduction of the less "salient" tax (employer contributions), coupled with an increase of the most "salient" tax (employee contributions). They differ according to the effect they have on total tax revenue. Reform 1 reduces tax revenue, Reform 2 raises tax revenue, and Reform 3 keeps it constant. Reform 1 unambiguously raises employment, while the positive effect of reforms 2 and 3 on employment depends on whether Condition (7) holds or not. The effect on welfare is also positive whenever there is an increase in the equilibrium employment level. I find that there is a trade-off between the two objectives of increasing employment and raising tax revenue.

I think it is interesting to remark how a simple model with a representative agent can still produce interesting policy conclusions. Clearly, a model with heterogeneous individuals would be even more interesting, since I could model different individuals as suffering from different degrees of myopia. I leave this extension for future work.

I also show that the main results carry over to a search and matching model in which there is equilibrium unemployment. That is, the same reforms I have studied in the partial competitive model, now have the effect of reducing equilibrium unemployment when applied to the MP model.

As a final comment I want to mention the effects of a simple policy that consists of making employer contributions more salient to workers. One example in this line was the decision of the Social Security Administration in the USA to send the so-called Social Security Statement to all workers paying payroll taxes. ${ }^{18}$ The Social Security Statement of a fictional worker, called "Wanda Worker," can be downloaded from the US Social Security website. It contains a detailed account of taxes paid both by the worker and by her employers throughout her full working career to present. A similar idea could be easily implemented in other countries, such as Spain, at a low cost. Another possibility could be to include information about employer contributions in the monthly statements that workers receive. In terms of my simple model, this would amount to raise the value of $\varphi$. Within the model of Section 2 it is immediate to show that this simple policy has always a positive effect on employment. The intuition is straightforward. Making employer contributions more salient to workers has no effect on labor demand, but it has a positive effect on supply, as long as firms pay contributions $\left(\tau_{F}>0\right)$ and workers give them some value $(\delta>0)$. This policy measure entails few costs and can prove useful

\footnotetext{
${ }^{18}$ See Mastrobuoni (2011).
} 
for increasing employment. ${ }^{19}$ In fact, this was one of the proposals in the report that the Swedish government commissioned to analyze the country's economic crisis in the Nineties. Quoting the report:

"42. Taxes should be made as visible as possible; they should also be called taxes and not fees; the gross wage, including payroll taxes, should be reported along with the wage payment." (Lindbeck et al. (1994, p. 103)).

\footnotetext{
${ }^{19}$ In the context of the MP model of Section 3, this policy change has always the effect of reducing the equilibrium level of unemployment. The reason is that it only affects the wage curve, shifting it to the right, while it does not affect the job creation curve.
} 


\section{References}

[1] Boeri, T., A. Börsch-Supan and G. Tabellini (2001): "Would you like to shrink the welfare state? A survey of European citizens," Economic Policy 16 (32), 7-50.

[2] Buchanan, J., and R. Wagner (1977): Democracy in Deficit, Academic Press.

[3] Cabral, M. and C. Hoxby (2012): "The Hated Property Tax: Salience, Tax Rates, and Tax Revolts," NBER Working Paper 18514.

[4] Chetty, R. (2009): "The simple economics of salience and taxation," NBER Working Papers No. 15246.

[5] Chetty, R., A. Looney and K. Kroft (2009): "Salience and Taxation: Theory and Evidence," American Economic Review 99(4): 1145-1177.

[6] Domínguez I., E. Devesa, M. Devesa, B. Encinas, R. Meneu, and A. Nagore (2010): "Encuesta para determinar el impacto de las reformas necesarias del sistema de pensiones español," Fundación Edad y Vida (http://www.edadvida.org/fitxers/news/119Premio\%20edadyvida2009.pdf)

[7] Dušek, L. (2002): "Visibility of Taxes and the Size of Government," Working Paper.

[8] Feldstein, M. and J.B. Liebman (2002): "Social Security," Chapter 32 in Handbook of Public Economics (A. J. Auerbach and M. Feldstein, editors), Volume IV, 2245-2324, Elsevier.

[9] Finkelstein, A. (2009): "E-Z Tax: Tax Salience and Tax Rates," Quarterly Journal of Economics 124 (3), 969-1010.

[10] Fullerton, D. and G. Metcalf (2002): "Tax incidence," Chapter 26 in Handbook of Public Economics (A. J. Auerbach and M. Feldstein, editors), Volume IV, 1787-1872, Elsevier.

[11] Goldin, J. and T. Homonoff (2013): "Smoke Gets in Your Eyes: Cigarette Tax Salience and Regressivity." American Economic Journal: Economic Policy 5 (1), 302-36.

[12] Goldin, J. (2013): "Optimal Tax Salience." Princeton University and Yale Law School. 
[13] Gruber, J. (1997): "The incidence of payroll taxation: evidence from Chile," Journal of Labor Economics 15 (3, pt.2), s72-s101.

[14] Hamermesh, D. S. (1993): Labour Demand Elasticity, Princeton University Press.

[15] Koskela, E. and R. Schöb (1999): "Does the Composition of Wage and Payroll Taxes matter under Nash Bargaining?," Economics Letters 64, 343-349.

[16] Lindbeck, A., P. Molander, T. Persson, O. Petersson, A. Sandmo, B. Swedenborg, and N. Thygesen (1994): Turning Sweden Around, The MIT Press.

[17] Mastrobuoni, G. (2011): "The Role of Information for Retirement Behavior: Evidence based on the Stepwise Introduction of the Social Security Statement," Journal of Public Economics 95, 913-925.

[18] Mortensen, D. T. and C. A. Pissarides (1994): "Job Creation and Job Destruction in the Theory of Unemployment," Review of Economic Studies 61, 397-415.

[19] Mulligan, C. and X. Sala-i-Martin (1999): "Gerontocracy, Retirement, and Social Security," NBER Working Papers No. 7117.

[20] Mulligan, C., R. Gil and X. Sala-i-Martin (2010): "Social Security and Democracy," The B.E. Journal of Economic Analysis and Policy 10, 1, 1-44.

[21] Pissarides, C. (1998): "The impact of employment tax cuts on unemployment and wages; The role of unemployment benefits and tax structure," European Economic Review 42 (1), 155-183.

[22] Pissarides, C. (2000): Equilibrium Unemployment Theory, The MIT Press.

[23] Saez, E., M. Matsaganis, and P. Tsakloglou (2012): "Earnings Determination and Taxes: Evidence from a Cohort based Payroll Tax Reform in Greece," Quarterly Journal of Economics 127 (1), 493-533.

[24] Salanié, B. (2003): The Economics of Taxation, The MIT Press.

[25] Summers, L. (1989): "Some simple economics of mandated benefits," American Economic Review 79 (2), 177-183.

[26] Tabellini, G., T. Boeri and A. Börsch-Supan (2002): "Pension reforms and the opinions of European citizens," American Economic Review 92 (2), 396-401. 


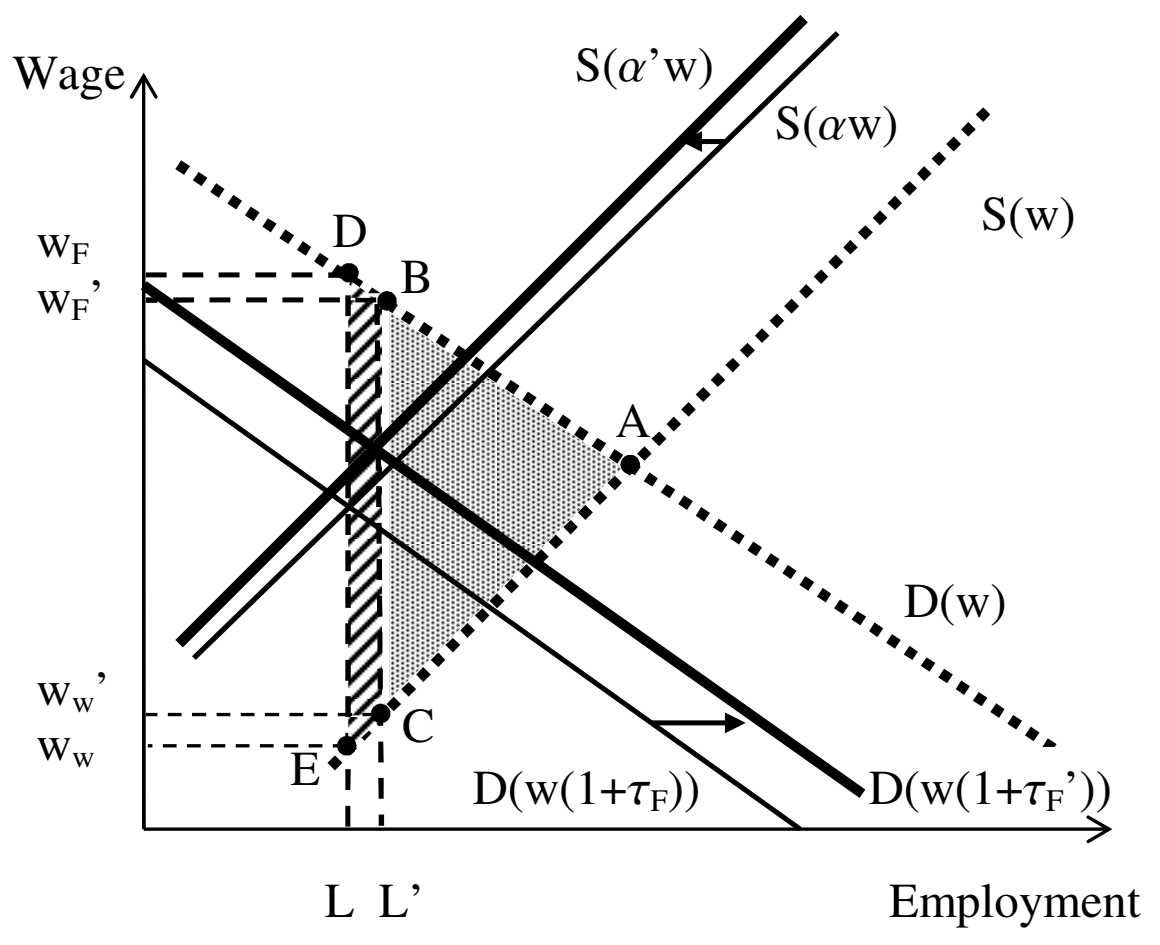

Figure 1: A reduction in employers' contributions 

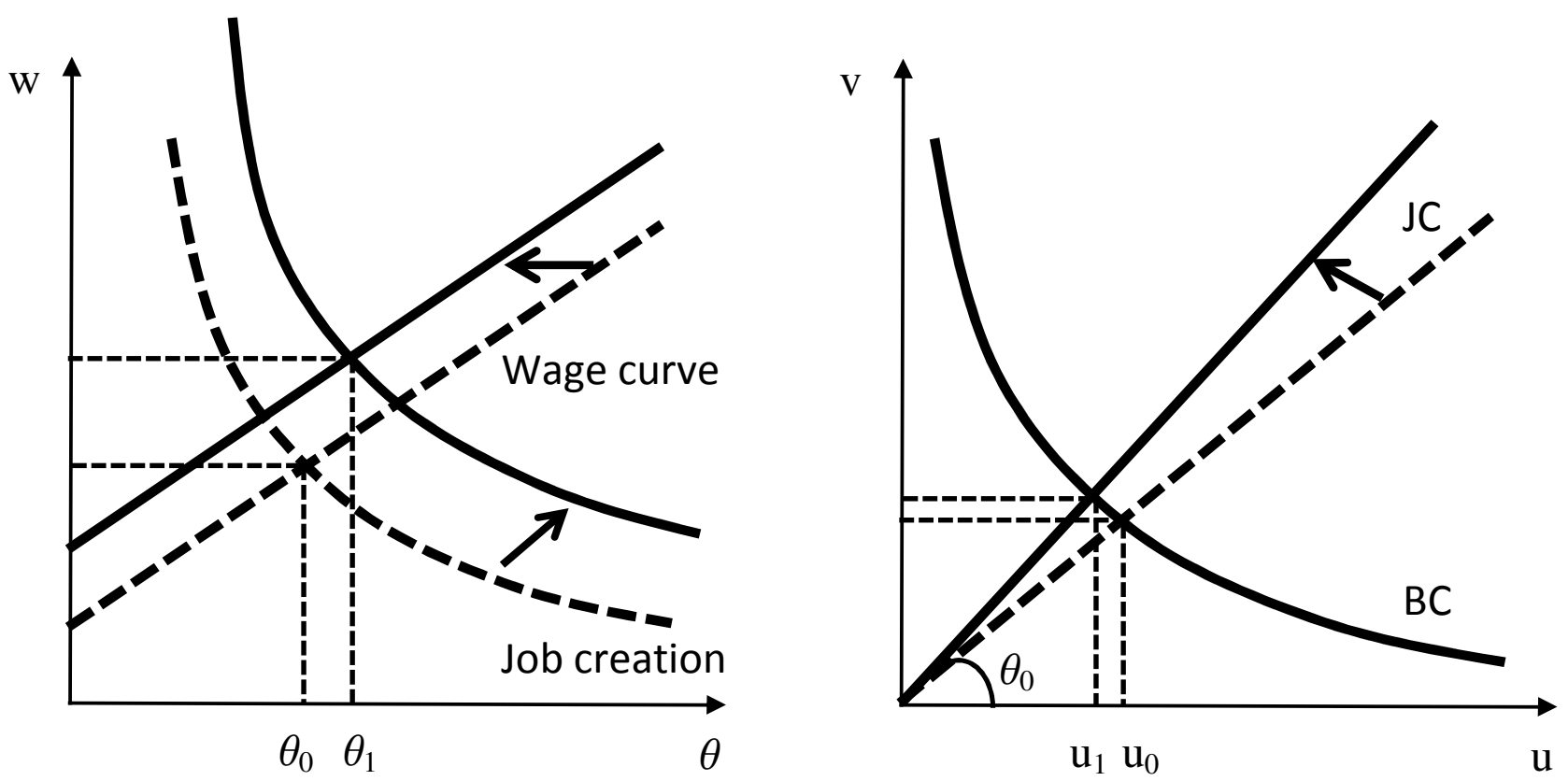

Figure 2: This policy reform reduces unemployment 


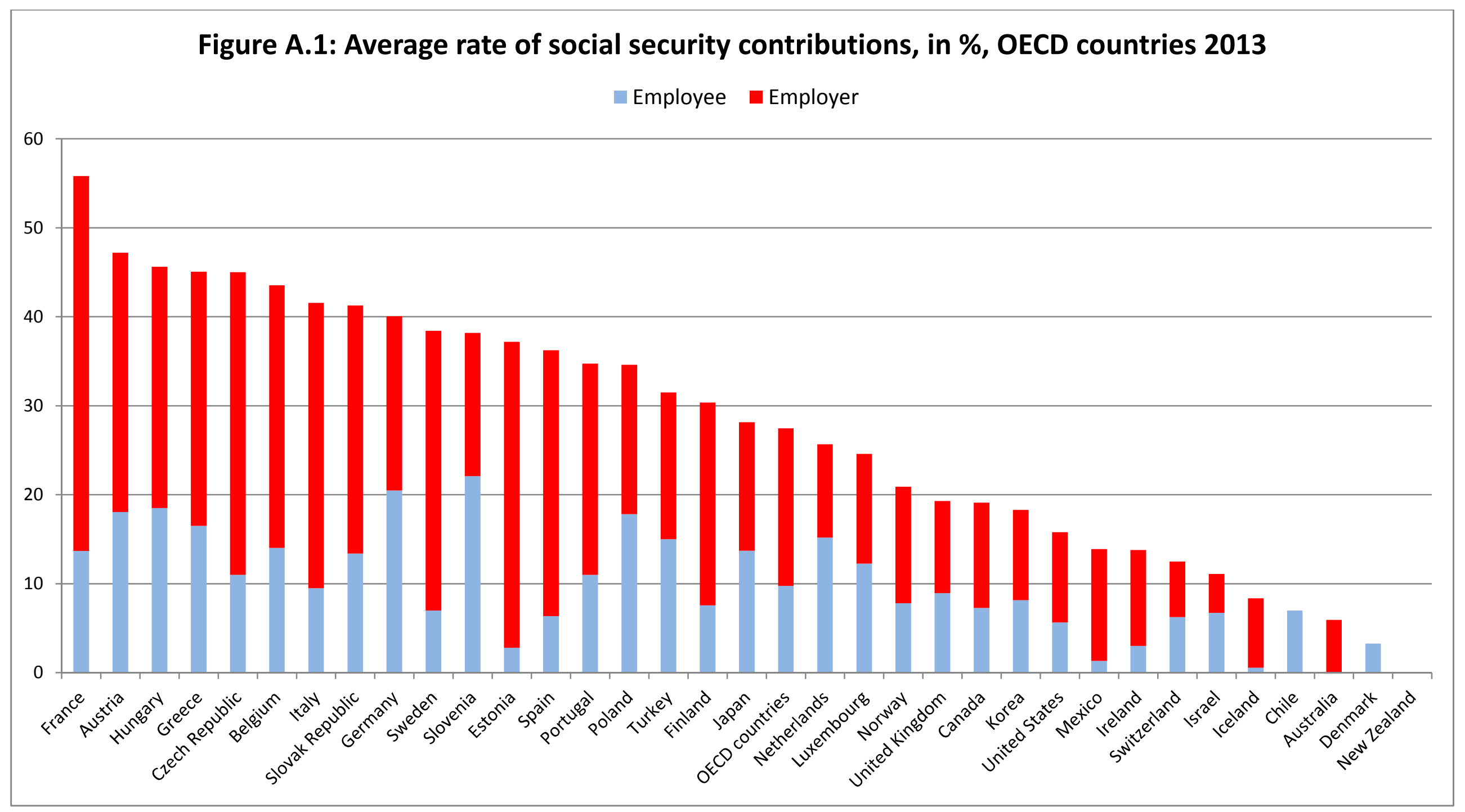

Notes: Data retrieved from the OECD database, December 2013 (http://stats.oecd.org/Index.aspx)

Data correspond to the average contributions for a two-earner couple, one at $100 \%$ of average earnings and the other at $67 \%$, with two children. 